УДК 340.12

А. В. Петров, А. А. Бирюков

\title{
РАЗВИТИЕ УЧЕНИЯ ОБ ОГРАНИЧЕННЫХ ВЕЩНЫХ ПРАВАХ НА НЕДВИЖИМОСТЬ В ВИЗАНТИЙСКОЙ ЮРИСПРУДЕНЦИИ ПОСЛЕ КОДИФИКАЦИИ ЮСТИНИАНА
}

В статье исследован вопрос становления и развития учения о правах ограниченного пользования чужими недвижимыми вещами (правах на чужие вещи) в юриспруденции Византийской империи. Автором публикации анализируются отечественная и зарубежная доктрина, Институции, Дигесты, юридические памятники Византийской империи, изданные после кодификации Юстиниана, в которых содержаться нормы вещного права, а именно о правах на чужие вещи

Используя сравнительно-правовой метод исследования, автор рассуждает о становлении доктрины ограниченных вещных прав в римской юриспруденции и раскрывает особенности развития догмы вещного права в юридических школах Византии. В статье подчеркивается, что развитие учений об ограниченных вещных правах на недвижимость в Западной Европе и в Византии происходило под влиянием различных факторов, среди которых называются социальные и политические процессы, становление феодального земельного права.

Автором анализируются такие сочинения византийских юристов как Парафраз Феофила, Индексы Стефана, Эклога, Василики, в которых нашли отражение нормы вещного права, разработанные в классической римской юриспруденции, а так же доктринальные разработки византийских юристов. В статье делается вывод о высоком уровне подготовке юристов византийских школ права, не уступающих в теоретических знаниях и законодательной технике классическим юристам Рима

Научная новизна представленной публикации заключается в том, что ее автором предпринята попытка выделить элементы научной теории в изложении взглядов византийских юристов на такую важнейшую часть гражданского права, как ограниченные вещные права на недвижимое имущество. В работе сделан вывод о научном характере византийских книг по цивильному праву а так же о серьезном вкладе антецессоров в дальнейшее развитие учения об ограниченных вещных правах. В этой связи подчеркивается, что византийскими юристами были научно проработаны такие вопросы как содержание ограниченных вещных прав на недвижимость, способы их возникновения, прекращения и защиты.

Ключевые слова: Вещные права, собственность Византийская юриспруденция, сервитут, суперфиций, эмфитевзис, узуфрукт.

\section{A. Petrov, A. Biryukov}

\section{THE DEVELOPMENT OF THE DOCTRINE OF LIMITED REAL RIGHTS TO REAL ESTATE IN BYZANTINE JURISPRUDENCE AFTER THE CODIFICATION OF JUSTINIAN}

The article examines the formation and development of studies on limited rights to non-owned property (rights to things belonging to other people) in the Byzantine Empire. The authors of the article analyze Russian and foreign doctrines, Institutions, Digests, legal monuments of the Byzantine Empire, published after the codification of Justinian, which contain the rules of property law, namely the rights to other people's things.

Using the comparative legal method of research, the author discusses the formation of the doctrine of limited property rights in Roman jurisprudence and reveals the features of the dogma of property law in the law schools of Byzantium. The article emphasizes that the development of the doctrine of limited property rights to real estate in Western Europe and Byzantium was influenced by various factors, including social and political processes, the formation of feudal land law.

The authors analyze such works of Byzantine lawyers as Theophilus Paraphrase, Stephen's Indices, Eclogues, Basilicorum, which reflect the rules of property law devel- oped in classical Roman jurisprudence, as well as doctrinal developments of Byzantine lawyers. The article concludes about the high level of training of lawyers of the Byzantine schools of law, not inferior in theoretical knowledge and legislative technique of classical lawyers of Rome.

The scientific novelty of the presented publication lies in the fact that the authors attempt to highlight the elements of scientific theory in the presentation of the views of Byzantine lawyers on such an important part of civil law as limited real rights to immovable property. The paper concludes on the scientific nature of Byzantine books on civil law, as well as on the serious contribution of the antecessors to the further development of the doctrine of the limited real rights. In this regard, it is emphasized that Byzantine lawyers were scientifically worked out such issues as the content of limited real rights to real estate, ways of their occurrence, termination and protection.

Key words: real rights, property, Byzantine jurisprudence, servitude, superficies, emphyteusis, usufruct. 
Разработка учения о вещном праве является одной из актуальных проблем отечественной и зарубежной юриспруденции. Принято считать, что первые зачатки такого учения появились еще в римском частном праве. Почву для научных рассуждений в этом ключе дают фрагменты сохранившихся до нашего времени памятников римского права и прежде всего, Институций (Institutiones) Гая, а также Дигест (Digesta (Pandectae), которые вошли составной частью в Corpus iuris civilis императора Юстиниана.

Римскому праву были известны следующие виды прав на чужие вещи:

- сервитуты (servitutes praediorum, servitutes urbanorum, servitutes personarum);

- суперфиций (superficies);

- эмфитевзис (emphyteusis)

- залоговое право (fiducia, pignus, hypotheca)

В гражданском законодательстве ряда европейских стран появление норм об ограниченных вещных правах на недвижимость стало результатом рецепции римского цивильного права. Именно римскими юристами были разработаны две юридические конструкции, ограничивающие власть собственника вещи - т.н. соседское право и обременение недвижимости ограниченными вещными правами других лиц (несобственников)

Принято считать, что предпосылками процесса рецепции римского права в континентальной Европе стала деятельность глоссаторов XI-XII| вв. а также политика первых европейских университетов, которые стали «проводниками» римских правовых традиций на рубеже XIII-XIV вв. Может сложиться ошибочное впечатление, что римское право стало известно в Европе только с момента открытия Т.н. Флорентийской рукописи Дигест (Littera Florentina) и составления первых глосс юристами Болонской школы права. Однако с падением Рима, римское право никуда не исчезло и, мало того, оно стало неотъемлемой частью правовых систем феодальных государств Раннего Средневековья.

На Западе, с конца V в. римское право, в том числе и право вещное подвергалось ревизии на предмет его соответствия новым условиям, которые были продиктованы социально-экономическими и политическими процессами, протекавшими в зарождавшихся государствах, объединивших племена франков, вестготов, бургундов и других народов, вышедших на историческую арену в эпоху Великого переселения.

Кроме того, в научных исследованиях, посвященных становлению доктрины вещного права, мы можем увидеть некий вектор, так же дающий не вполне правильное представление о том, что доктрина вещного права начала складываться исключительно в рамках деятельности глоссаторов и постглоссаторов, а оформилась уже в процессе деятельности немецкой школы частного права на рубеже XVIII-XIX вв. При этом в работах отечественных цивилистов, исследующих вопросы становления и развития института ограниченных вещных прав, почему то без должного внимания остается деятельность византийской школы права. Исключением является только обзоры законодательных работ комиссии Трибониана, под руководством, которого была проведена кодификация гражданского права. Поэтому в рамках данного исследования будет предпринята попытка дать оценку влияния деятельности византийских юристов на становление учения об ограниченных вещных правах, причем основной акцент будет сделан на анализе работ юристов постюстиниановской эпохи.

Начать следует с того, что в отличие от новых варварских королевств, зарождавшихся на обломках Западной Римской империи, на Востоке ревизия римского права имела иные цели и подоплеку. К началу V в., когда Римская империя окончательно распалась на две части - Западную и Восточную (Византию), римское право представляло собой огромный массив императорских конституций, указов, сенатконсультов, эдиктов магистратов (преторского права), сочинений старых республиканских и классических юристов.

По мнению историков права, такое положение дел со временем породило две основные проблемы. Во-первых, наличие разрозненных и разнородных по своей сути и внешнему выражению норм источников права начало создавать сложности для правоприменительной практики. Это было связано с тем, что на фоне общего упадка юриспруденции, судьи и практики не всегда имели под рукой тексты сочинений старых признанных юристов, на которые можно было ссылаться.

Ввиду позднейших наслоений сами тексты могли противоречить друг другу, что по выражению М. В. Левченко, давало возможность византийским чиновникам «ловить рыбу в мутной воде», т.е. принимать заведомо неправильные решения, затягивать процессы, вымогать мзду [10, с. 62]. Здесь можно сказать и о негативном влиянии неформальной “конкуренции» между взглядами и высказываниями классических юристов. Для устранения этого пробела даже был принят специальный закон (426 г.), который перечислял обязательные и имеющие юридическую силу сочинения юристов, в числе которых были Папиниан, Павел, Ульпиан, Гай и Модестин, а так же те юристы, ссылка на которых допускалась, поскольку взгляды последних не противоречили взглядам вышеназванной «пятерки».

Во-вторых, громоздкое и несистематизированное многовековое наследие римской юриспруденции мешало нормальному функционированию административного аппарата Византии [10, с. 62], а так же качественному отправлению правосудия. И если в последние десятилетия существования Западной Римской империи, власть императора, как и сама римская государственность, была расшатана и ослабевала, то на Востоке, в Константинополе такая власть, наоборот, набирала силу и требовала понятного и единого законодательства, которое бы действовало на всей территории государства и распространялось на все категории населения. Процесс ревизии римского 
права в Восточной Римской империи получил название кодификации, которая была завершена в 30-х годах VI в. Итогом данной масштабной работы стали:

- Институции (обнародованы 21 ноября 533 г.)

- Дигесты или Пандекты (обнародованы 16 декабря 533 г.)

- Кодекс (обнародован 16 ноября 534 г).

Последняя часть Свода - Новеллы была систематизирована уже после работы комиссии Трибониана.

Оставляя в стороне особенности проведения работ по систематизации римского права византийскими правоведами, необходимо отметить, что данный процесс был многоэтапным и занял не одно десятилетие, поскольку первые попытки упорядочить правовое наследие Рима были предприняты задолго до Юстиниана в IV-V в. Из наиболее поздних работ здесь можно назвать кодекс императора Феодосия (Codex Theodosianus), который был издан в 438 г. Кроме того, необходимо также учесть, что на Востоке стараниями императоров династий Валентиниана - Феодосия, Львов и Юстиниана доминирующим становилось римское право, в отличие от Запада, где «романизация) законодательства новых королевств носила локальный характер

Как развивалась юридическая наука и знания о вещном праве в ранней Византии? С уверенностью можно сказать, что после общего упадка классической римской юриспруденции сочинения и высказывания новых юристов уже не являлись источником права, в отличие от трудов их предшественников, творивших в период поздней Республики и принципата. Конечно юриспруденция после III в. никуда не исчезла, просто работа юристов, которые практиковали в период Поздней империи, приобрела иной, можно сказать прикладной характер, «из искусства стала простым ремеслом» [13, с. 674]. Причиной такого качественного изменения практически единогласно, признается, с одной стороны - общий упадок римской культуры и, с другой стороны - усиление императорской власти и появление императорских конституций, как основного источника права $[14$, c. $16 ; 2$, c. 114$]$

Доказательством выше сказанному служит тот факт, что в тех же Дигестах мы не найдем фррагментов, отсылающих к мнениям юристов, занимавшихся юриспруденцией после Гермогениана (Hermogenianus) или Аврелия Аркадия Харизия (Aurelius Arcadius) т.е. со второй половины IV в. Конечно это не говорит о том, что в Римской империи на Западе и на Востоке больше не было именитых юристов. Исследователи римского права отмечают, что в IV-V в., были известны такие правоведы как: Кирилл, Домнин, Демосфен [14, c. 16]. Сохранились сведения о достаточно долгом функционировании известных юридических школ - лександрийской, Афинской, Беритской (Бейрутской), Константинопольской, в которых работали и преподавали авторитетные юристы $[1$, c. $63-64 ; 8$, с. $16 ; 9$, c. 360$]$.
Те юридические школы, которые существовали на территории Византии, осуществляли не только обучение будущих юристов. Профессора этих школ занимались переводом юридических памятников с латыни на греческий, принимали активное участие в работе комиссии Трибониана по составлению Институций, Кодекса, Дигест. По крайней мере, источники упоминают о четыpex известных византийских ученых правоведах (Феофил, Дорофей, Анатолий, Грациан), которых византийские чиновники привлекли к работе над сводом римского права $[15$, с. 537].

Считается, что деятельность византийских юристов содержательно и методологически отличалась от деятельности их предшественников классических юристов Рима. Ученые признают, что классики эпохи принципата были «увлеченными мастерами казуистики», и не решались давать определения основных категорий гражданского права, в частности это касается и ограниченных вещных прав [9, с. 367]. По крайней мере, мы можем судить об этом по тем фрагментам юридической литературы античного Рима, которая с искажениями или без, сохранилась до наших дней. Однако в высказываниях юристов республиканского и имперского Рима, при отсутствии дефиниций с одной стороны, с другой, присутствовал тот самый «разносторонний и тонко диффееренцированный анализ», который дает основание полагать, что дефиниции и правила считались у римских юристов синонимами $[9$, с. 366]. Четкость и определенность выражения своих мнений - вот что, по мнению И. С. Перетерского, отличало классических юристов от «византийских компиляторов» $[9$, с. 14$]$.

В этом вопросе конечно можно согласиться с И. С. Перетерским, если только принимать во внимание деятельность только тех самых «компиляторов», иными словами команду юристов Трибониана, которая по иронии судьбы, занималась сведением в единое целое сохранившиеся части юридического наследия римских «классиков» права. Но эпоха компиляторов - это только одно неполное столетие во всей многовековой истории правовой культуры Византии, а вся история византийской юриспруденции после Юстиниана - еще несколько сотен лет работы в области законотворчества, юридического образования, а так же и научной деятельности не одного поколения правоведов.

Кроме того, сам процесс кодификации частного права, назвать простой компиляцией или «бюрократической» юриспруденцией можно с большой долей условности. Так, задачи, которые были поставлены перед комиссией Трибониана, были гораздо сложнее, чем может показаться на первый взгляд. Например, те же Дигесты, дающие нам представление об ограниченных вещных правах, структурно отличаются от иных частей кодификации, да и вообще от любого источника права, поскольку в каждом фрагменте имеется указание на конкретного римского юриста и его сочинение. Но Дигесты - это не антология юридической мысли 
Древнего Рима, а свод действующих, правовых норм, обязательных к применению на всех территориях, находившихся под властью Константинополя. Собрать и систематизировать в рамках единого «сборника» огромное количество непростого и не типичного по своей природе нормативного материала - задача трудновыполнимая даже для современного юриста, вооруженного самым совершенным инструментарием законодательной техники.

После кодификации Юстиниана дальнейшее направление развития византийской юридической мысли отчасти было обусловлено прямым запретом какого либо глоссирования или интерпретирования Дигест. Этот запрет был установлен императорским указом (Constitutio Tanta) 16 декабря 533 г. После обнародования результатов работы комиссии Трибониана юристам разрешалось делать только переводы юридических текстов на греческий язык, но «в том же порядке и в той же последовательности, в которых они размещены и в римских выражениях» [5, с. 65]. В качестве исключения, допускаемого \$21 Constitutio Tanta, юристам так же разрешалось делать при-

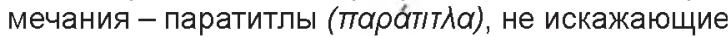
оригинального текста Дигест.

Ограничению догматического толкования новых текстов должны были способствовать изменения, касающиеся «программы» юридического образования после обнародования Дигест. Из положений императорского указа Constitutio Omnem можно проследить намерение Юстиниана пресечь вольное толкование Институций и Дигест при помощи сокращения юридических школ, в которых, в результате неправильного обучения юристов мог искажаться смысл официальных источников права. Само же право в признанных императорской властью школах, должно было изучаться в той последовательности, которая закреплялась §2-5 Constitutio Omnem. Профресcopa византийских школ, допущенные к преподаванию права, именовались антецессорами (antecessoris) и их число постепенно увеличивалось [9, с. 362].

Большинство специалистов в области Византийского права полагают, что Юстинианов запрет не возымел должного эффекта, стал т.н. «мертвой буквой» [6, с. 274] и через какое-то время те же профрессора права начали давать подробные (пусть сначала и устные) догматические комментарии на отдельные титулы и фррагменты отдельных частей Свода.

Ярким примером таких комментариев является сохранившийся до наших дней и выдержавший несколько изданий Парафраз Феофила (Paraphrasis Theophili). Дошедшие до нас рукописи лекций, которые константинопольский профессор Феофил читал своим ученикам, объединенные затем в единый труд, дают ценные сведения и о теоретических представлениях византийских юристов относительно ограниченных вещных прав.

Paraphrasis Theophili - это интерпретация Институций, которые согласно §2 Constitutio Omnem были предписаны к изучению в первый год обучения в юридических школах Константинополя или Бейрута.

Феофил являлся одним из главных компиляторов Corpus iuris civilis, поэтому он как никто иной имел представление и о первоначальном содержании тех источников (в первую очередь Институций Гая), на основе которых были составлены Институции Юстиниана и о тех местах, которые исправлялись или удалялись в процессе работы над имевшимися в распоряжении комиссии Трибониана древними текстами. Вообще, считается, что Феофил преподавал и Дигесты [9, с. 364], поэтому можно предположить, что его научный потенциал был гораздо шире тех знаний, которые были необходимы для постижения юриспруденции lustinianos novos («новыми Юстинианами») студентами первогодками юридических школ.

По аналогии со структурой Институций Paraphrasis Theophili состоит из четырех книг Ограниченным вещным правам посвящается материал, расположенный в 3-4 титулах второй книги - De servitutibus; De usufructu; De usu et habitatione. Рассуждения Феофила о вещных и личных сервитутах выходят за пределы текста Институций. При этом Феофил активно использует те самые паратитлы, т.е. обращается к другим титулам Институций для пояснения тех или иных правил. В качестве примера можно привести комментарии к титулу De rebus incorporalibus, где Феофил, поясняя природу вещей (в данном случае т.н. «бестелесных» вещей), в качестве примеров таких вещей приводит сервитуты, узуфрукт и habitatio [21, p. 105-106]

Несмотря на то, что изначально Парафраз это сборник лекций, воссозданный по записям учеников Феофила, по способу изложения данный труд все же ближе к классическому комментарию. Стиль и логика подачи материала в Парафразе отличается от сухого стиля Институций и пространственного дискурса Дигест. Может быть этим, отчасти объясняется «популярность» Парафраза среди византийских юристов, которые в своей практике руководствовались им вместо оригинала Институций Юстиниана, даже в то время, когда Юстинианово законодательство «...уже было забыто на Востоке» $[1$, с. 80]

История сохранила имена и других выдающихся юристов постюстиниановской эпохи - Феодора Гермупольского (Theodorus Hermopolis), Кобида (Gobidas) или Кубидия, Филоксена (Philoxenes), Сумбатия (Symbatius), Анастасия (Anastasius) и др. Научная и преподавательская деятельность этих юристов знакома нам только по цитатам и сохранившимся коротким фрагментам. Принято считать, что их главная заслуга заключается в том, что они смогли не только перевести на греческий, но и адаптировать весь законодательный массив к потребностям юридической практики [20, p. 498].

Догматические представления византийских юристов об ограниченных вещных правах можно обнаружить еще в одном виде юридической ли- 
тературы того времени - т.н. Index или Summae. Индексы - это краткое содержание юридического текста в порядке его расположения. Наряду с паратитлами индексы являлись исключением из общего запрета вольной научной интерпретации официальных текстов Институций, Дигест и Кодекса Юстиниана. Исследователи приписывают авторство индексов к отдельным частям Дигест знаменитым профессорам права Феофилу, Дорофею, Кириллу, Стефану [19, p.498].

Стесран (Stephanus) - профессор Константинопольской или Бейрутской школы, перу которого принадлежат комментарии к Дигестам, получившие название «Index». Специалисты полагают, что индексы Стефрана в то время являлись лучшим юридическим произведением, раскрывающим сущность Дигест, которое было популярно, в том числе и у юристов практиков $[11$, с. 73$]$.

В своих комментариях Стефан не обошел стороной и ограниченные вещные права. Так сохранились комментарии (индексы) Стефана к 7 книге Дигест об узуфрукте, 8 книге о сервитутах. Сам труд Стефана в целом виде до нас не дошел. Однако с его многочисленными индексами мы можем ознакомиться, прежде всего, по сохранившимся рукописям одного из самых известных памятников византийской правовой культуры Василик (конец IX в.). Эти рукописи с пояснениями (т.н. схолиями) относительно содержания отдельных титулов Василик, дают представление о творчестве не только Стефана, но и других известных юристов Византии VI в. Как полагает А. П. Каждан, греческий перевод и пересказ норм римского права, который можно найти в Василиках, выполнен не в IX, а в VI в. [7, с. 59]. В качестве примера можно обратиться к 16 книге Василик, которая посвящается узуфррукту. Помимо выдержек из Индекса Стефана, книга снабжена извлечениями из Индекса Кирилла, Суммы Анонима (Anonymus), произведений Энантиофана (Enantiophanes) [18].

Многогранность деятельности византийских юристов можно проследить не только по разнородной юридической литературе, но достижениям в области законодательной техники. После кодификации Юстиниана императоры Константинополя продолжали издавать новеллы, которые представляли собой законы, регулирующие отдельные общественные отношения в меняющихся социальных, политических и экономических условиях.

Ученые делают выводы о том, что те правовые конструкции (а это касается и вещно-правовых институтов), которые мы можем найти в Corpus iuris civilis, со временем перестали в полной мере отвечать специфическим процессам, сопровождавшим эволюцию Византийского государства. Так, в качестве примера можно привести Земледельческий закон (Nomos georgikos) - памятник византийского аграрного права конца VII - первой половины VIII века. В литературе даты принятия данного закона вызывают разногласия. Например, в фундаментальном исследовании
«Византийский земледельческий закон», подготовленным И. П. Медведевым, Е.Э Липшиц и Е. К. Пиотровской датой создания архетипа данного закона называется период между 533 и 572 г [3, с. 140]. Существует противоположное мнение, что авторство Nomos georgikos принадлежит юристам (юристу), периода деятельности антецессоров [3, с. 140-141]. Данный закон отражает особенности т.н. переходного периода в истории Византии, который, по мнению М. Я. Сюзюмова показывал «преобладающее место» свободной крестьянской общины в аграрной жизни государства, т.е. в тот момент, когда земледелие, основанное на рабском труде отмирало, а феодальные институты еще только начинали формироваться [16, с. 46].

Специалисты признают, что в данном законе прослеживается минимальное влияние кодификации Юстиниана и наоборот, сильное влияние права обычного. Этот закон представлял собой «совсем новое право» и имел больше сходства с варварскими правдами [12, с. 154]. Помимо права собственности на землю данный закон регулирует вопросы соседского права $(\$ 7, \S 31)$, а в §82-84 затрагиваются вопросы проведения воды через чужие участки - аналога водного сервитута aquaeductus. Ю. Я. Вин отмечает, что в ряде положений закона, касающихся сбора фруктов для собственных нужд, сенокоса, выпаса скота видны пережитки позднеримских сервитутов [4, с. 44-45].

Владение серьезной законодательной техникой византийских юристов демонстрирует еще один памятник права - Эклога. В отличие от новелл Эклога, это не просто закон - а свод законов, т.е. по сути, первая серьезная компиляция после законодательных работ Юстиниана І. Оставляя в стороне исторические подробности создания Эклоги и ее прототипов, отметим, что появление этого законодательного свода приблизительно в 726 г. стало еще одной значимой вехой византийской юриспруденции. Считается, что Эклога ни в коей мере не отменила узаконения Юстиниана, а привнесла в византийское право законоположения, без которых регулировать те или иные правоотношения стало просто невозможным. Здесь можно предположить, что ко времени правления императоров Исаврийской и Македонской династий в силу объективных причин адаптировать часть старых правовых конструкций Дигест или других частей свода Юстиниана к новым условиям у юристов попросту не получалось. Поэтому Эклога состоит из положений, которые на тот момент, по замыслу составителей, представляли «жизненный интерес для византийского общества VIII в.» $[17$, с. 37]

Работая над Эклогой, византийские юристы не обошли стороной и ограниченные вещные права на недвижимость. XII Титул Эклоги получил название «О вечном и ограниченном эмфитевзисе». Как мы знаем для византийского аграрного права эмфитевзис - это далеко не новый институт. Эмфитевзису даже предписывается не римское, 
а именно греческое происхождение. В своде Юстиниана эмфитевзису посвящается 66 титул Кодекса De emphyteutico iure, и в принципе общие положения Кодекса об эмфитевзисе повторяются в Эклоге. Но составители Эклоги разработали и новые положения, отразившиеся в содержании ст. 1-6 XII Титула, которые касаются предельных сроков существования права, ограничений на использование конструкции эмфитевзиса (приобретение или передачу) отдельными лицами (церковью, дийокетами, стратиотами, и т.д.).
Таким образом, становление и развитие классической доктрины вещного права и его неотьемлемой части - ограниченных вещных прав невозможно рассматривать в отрыве от тех взглядов и идей, которые оставили нам византийские правоведы, юридическое научное наследие которых представляет интерес как в контексте изучения истории права Византии, так и частного права в целом.

\section{Литература}

1. Азаревич Д. И. История византийского права. Т.1. Ярославль: Тип. Г. В. Фалька, 1876. 476 с.

2. Аннерс Э. История европейского права. М.: Наука, 1994. 397 с

3. Византийский земледельческий закон / под ред. И.П. Медведева. Л.: Наука, 1984. 280 с.

4. Вин Ю. Я. «Земледельческий закон» - источник правового регулирования и коллективного самоосознания сельской общины в средневековой Византии // Вестник ВолГУ. Серия 4, История, Регионоведение, Международные отношения. 2016. Т.21. №5. С. 44-45.

5. Дигесты Юстиниана / перевод с латинского; отв. ред. Л. Л. Кофанов. Том 1. М.: Статут, 2002. 584 с.

6. Диль Ш. Юстиниан и Византийская цивилизация в VI в. СПб.: Типография Альтшулера, 1908. 741 с

7. Каждан А.П. Василики как исторический источник // Византийский временник. Том 14. М.: Издательство Академии наук СССР, 1958. С. 56-66.

8. Крылов Н. И. Об историческом значении римского права в области наук юридических. М.: Унив. тип., 1838. 20 с.

9. Левченко М. С. История Византии. Краткий очерк. М.,Л.: Соцэкгиз, 1940. 273 с.

10. Липшиц Е. Э. Законодательство и юриспруденция в Византии в IX-XI вв. Историко-юридические этюды. Л.: Наука, 1981. 246 с

11. Липшиц Е. Э. Славянская община и ее роль в формировании византийского феодализма // Византийский временник. Том.1. М.: Издательство Академии наук СССР, 1947. С. 144-164.

12. Муромцев С. А. Гражданское право древнего Рима. М.: Тип. А. И. Мамонтова и Ко, 1883. 733 с

13. Культура Византии IV - первая половина VII в. М.: Наука, 1984. 723 с

14. Перетерский И. С. Дигесты Юстиниана. Очерки по истории составления и общая характеристика. М.: Юридическая литература, 1956. 129 с.

15. Пухта Г. Ф. История римского права. М.: Тип. Семена, 1864. 585 с.

16. Сюзюмов М. Я. О характере и сущности византийской общины по земледельческому закону. // Византийский временник. Том. 10. М.: Издательство Академии наук СССР, 1956. С. 27-48.

17. Эклога. Византийский законодательный свод VIII века. М.: Наука, 1965. 228 с

18. Basilicorum. Lib. XV-XIX. Lipsiae, 1846. 288 p.

19. Berger A. Encyclopedic dictionary of Roman law. Philadelphia, 1991. $476 \mathrm{p}$

20. Ortolan J. The history of Roman Law. London, 1871. 709 p.

21. Theophili Paraphrasis Justiniani Institutionum. Amstelodami, 1860. 456 p.

\section{References}

1. Azarevich D. I. Istorija vizantijskogo prava. (The History of Byzantine law). Vol. 1. Yaroslavl: G.V. Fal'k's printing house, 1876. 476 p. (In Russian).

2. Anners Je. Istorija evropejskogo prava (The history of European law). Moscow: Nauka publ., 1994. 397 p. (In Russian).

3. Vizantijskij zemledelcheskij zakon (Byzantine agricultural law) / ed by I.P. Medvedev. Leninggard: Nauka publ., 1984. 280 p. (In Russian).

4. Vin J. «Zemledelcheskij zakon» - istochnik pravovogo regulirovanija i kollektivnogo samoosoznanija sel'skoj obshhiny $v$ srednevekovoj Vizantii (The farmer's law (nomos georgikos) - source of law regulation and collective self-consciousness of rural community in medieval Byzantine) // Vestnik VolGU. Serija 4. Istorija, Regionovedenie, Mezhdunarodnye otnoshenija. 2016. Vol.21. No.5. P. 44-45. (In Russian).

5. Digesty Justiniana (Digest of Justinian) / translator and editor - L. L. Kofanov. Vol. 1. Moscow: Statut, 2002. 584 p. (In Russian).

6. Dil' Sh. Justinian i Vizantijskaja civilizacija v VI v. (Justinian and Byzantine civilization in the sixth century). St.Petersburg Altshuler's printing house, 1908. 741 p. (In Russian).

7. Kazhdan A. P. Vasiliki kak istoricheskij istochnik (Vasiliki as a historical source) // Vizantijskij vremennik. Vol 14. Moscow: SA USSR publ., 1958. P. 56-66. (In Russian)

8. Krylov N. I. Ob istoricheskom znachenii rimskogo prava v oblasti nauk juridicheskih (On the historical significance of Roman law in the field of legal sciences). Moscow: University printing house, 1838. 20 p. (In Russian).

9. Levchenko M. S. Istorija Vizantii. Kratkij ocherk (The history of Byzantine). Moscow, Leningrad: Socjekgiz, 1940. 273 p (In Russian).

10. Lipshic E. Je. Zakonodatel'stvo i jurisprudencija v Vizantii v IX-XI vv. Istoriko-juridicheskie jetjudy (Legis/ation and jurisprudence in Byzantine in IX-XI centuries. Historical and legal studies). Leningrad: Nauka publ, 1981. 246 p. (In Russian) 
11. Lipshic E.Je. Slavjanskaja obshhina i ee rol' v formirovanii vizantijskogo feodalizma // Vizantijskij vremennik (The Slavic community and its role in the formation of Byzantine feudalism). Vol. 1. Moscow: SA USSR publ., 1947. P. 144-164. (In Russian)

12. Muromcev S. A. Grazhdanskoe pravo drevnego Rima (The civil law of ancient Rome). Moscow: A.I. Mamontova and Ko publ., 1883. 733 p. (In Russian).

13. Kul'tura Vizantii IV - pervaja polovina VII v. (The culture of Byzantine IV-first half of VII century). Moscow: Nauka publ. 1984. 723 p. (In Russian).

14. Pereterskij I. S. Digesty Justiniana. Ocherki po istorii sostavlenija i obshhaja harakteristika (Digest of Justinian. Essays on the history of compilation and General characteristic). Moscow: Juridicheskaja literature publ, 1956.129 p. (In Russian).

15. Puhta G. F. Istorija rimskogo prava (The history of Roman Law). Moscow: Semen's printing house, 1864.585 p. (In Russian)

16. Sjuzjumov M. Ja. O haraktere i sushhnosti vizantijskoj obshhiny po zemledel'cheskomu zakonu (On Character and Essence of Byzantine Community According to the Farmer's Law) // Vizantijskij vremennik. Vol. 10. Moscow: SA USSR publ. 1956. P. 27-48. (In Russian).

17. Jekloga. Vizantijskij zakonodatel'nyj svod VIII veka (Ecloga. Byzantine legislative code of the VIII century). Moscow Nauka, 1965. 228 p. (In Russian).

18. Basilicorum. Lib. XV-XIX. Lipsiae, 1846. $288 p$

19. Berger A. Encyclopedic dictionary of Roman law. Philadelphia, 1991. $476 p$

20. Ortolan J. The history of Roman Law. London, 1871. 709 p.

21. Theophili Paraphrasis Justiniani Institutionum. Amstelodami, 1860. 456 p

\section{Сведения об авторах}

Петров Александр Васильевич - доктор юридических наук, профессор кафедры кафедры гражданского права и процесса юридического института Северо-Кавказского федерального университета (Ставрополь) / petrov_av2012@mail.ru

Бирюков Александр Александрович - кандидат юридических наук, доцент кафедры гражданского права и процесса юридического института Северо-Кавказского федерального университета (Ставрополь) / kafcivil@yandex.ru

\section{Information about the authors}

Petrov Alexandr - Doctory of Law, Professor, Chair of Civil Law and Process, Law Institute, NorthCaucasus Federal Universiry (Stavropol) / petrov_av2012@mail.ru

Biryukov Alexandr - PhD in Law, Associate-Professor, Chair of Civil Law and Process, Law Institute, North-Caucasus Federal Universiry (Stavropol) / kafcivil@yandex.ru 